\title{
The oncostatin $M$ receptor/gp130 ligand murine oncostatin $M$ induces apoptosis in adrenocortical Y-1 tumor cells
}

\author{
Christoph J Auernhammer*, Franziska Dorn*, George Vlotides, \\ Sabine Hengge, Florian B Kopp, Gerald Spoettl, Neziha Cengic, \\ Dieter Engelhardt and Matthias M Weber ${ }^{1}$
}

\begin{abstract}
Department of Internal Medicine II, Klinikum Grosshadern, Ludwig-Maximilians-Universität, Marchioninistr. 15, Munich 81377, Germany
${ }^{1}$ Department of Internal Medicine I, Division of Endocrinology and Metabolism, Universität Mainz, Mainz, Germany

(Requests for offprints should be addressed to Christoph J Auernhammer; Email: Christoph.Auernhammer@med2.med.uni-muenchen.de)

*(Christoph J Auernhammer and Franziska Dorn contributed equally to this article)
\end{abstract}

\begin{abstract}
The effects of murine oncostatin M (mOSM) are specifically mediated by the heterodimeric oncostatin $\mathrm{M}$ receptor (OSMR)/gp130 receptor complex. In the current study we demonstrate that murine adrenocortical Y-1 tumor cells express the OSMR/gp130 complex. Incubation of Y-1 cells with 1 and $10 \mathrm{ng} / \mathrm{ml} \mathrm{mOSM}$ induces cell death due to specific induction of apoptosis. Western blot analysis of Y-1 cells incubated with mOSM for $24 \mathrm{~h}$ revealed caspase-3 cleavage and poly(ADP-ribase) polymerase (PARP) cleavage. In a proliferation assay system, incubation of Y-1 cells with $0 \cdot 01,0 \cdot 1,1$ and $10 \mathrm{ng} / \mathrm{ml}$ mOSM for $24 \mathrm{~h}$ resulted in a decrease in cell numbers to $99 \pm 2 \%, 84 \pm 9 \%, 50 \pm 7 \%$ and $43 \pm 5 \%$ respectively of untreated control (defined as 100\%). Pretreatment of Y-1 cells with the Jak2 inhibitor AG490 $(100 \mu \mathrm{M})$ rescued Y-1 cells from OSM-induced $(10 \mathrm{ng} / \mathrm{ml})$ cell death. Similarly, pretreatment of Y-1 cells with the general
\end{abstract}

caspase inhibitor Z-VAD-FMK $(42 \mu \mathrm{M})$ rescued $\mathrm{Y}-1$ cells from OSM-induced $(10 \mathrm{ng} / \mathrm{ml})$ cell death.

In summary, we show that adrenocortical Y-1 tumor cells express the OSMR/gp130 complex and that mOSM induces the Jak-STAT signaling cascade in these cells. Murine OSM in a dose-dependent manner induces apoptosis in adrenocortical Y-1 tumor cells. Apoptosis was demonstrated by caspase-3 cleavage and PARP cleavage. Rescue of Y-1 cells from mOSM-induced apoptosis by the Jak2 inhibitor, AG490, and the general caspase inhibitor, Z-VAD-FMK, demonstrates Jak activation and subsequent caspase activation to be essential for MOSMinduced apoptosis in adrenocortical Y-1 tumor cells. The putative role of OSM as an immunotherapeutic agent in human adrenocortical cancer remains to be elucidated. Journal of Endocrinology (2004) 180, 479-486

\section{Introduction}

Oncostatin M (OSM) is a member of the gp130 cytokine family (Gomez-Lechon 1999, Heinrich et al. 2003, Tanaka \& Miyajima 2003). Signal transduction of gp130 cytokines encompasses activation of the Jak-STAT signaling cascade pathway as well as the ras-dependent MAP kinase (MAPK) pathway. Briefly, ligand binding to the gp130 receptor complex induces autophosphorylation of Janus kinases (Jak)s, followed by tyrosine phosphorylation of specific residues in the cytoplasmatic receptor domains and subsequent tyrosine phosphorylation of signal transducer and activator of transcription (STAT) factors. Phosphorylated STAT proteins (pSTATs) homo- or heterodimerize, translocate as dimers to the nucleus, and act as specific transcription factors binding to STAT binding elements in the promoter region of various genes. The tyrosine residue, Y757, in the cytoplasmatic domain of activated gp130 is essential for association of src homol- ogy 2 domain-bearing protein tyrosine phosphatase (SHP)-2 with gp130 and links Jak-mediated activation of gp130 to the ras-dependent MAPK pathway. Receptor complexes of gp130 cytokines are constituted by ligandspecific receptor subunits and the common receptor subunit gp130 (Heinrich et al. 2003).

In human cells, human OSM (hOSM) can bind to the OSM receptor (OSMR)/gp130 complex, but can also signal through the leukemia inhibitory factor receptor (LIFR)/gp130 complex (Lindberg et al. 1998, Tanaka et al. 1999, Wang et al. 2000). The LIFR/gp130 complex normally mediates signaling of LIF, another member of the gp130 cytokine family (Auernhammer \& Melmed 2000). Therefore, experiments using hOSM in human cell systems exhibit effects mediated either by the OSMR/gp130 or the LIFR/gp130 complex, or by both. Thus, the signaling pathway induced by hOSM is dependent on the cell-type specific expression pattern of OSMR, LIFR and gp130 receptor subunits respectively. In murine cells, 
hOSM cannot bind to the OSMR/gp130 complex, but only binds to the LIFR/gp130 complex. In contrast, signaling of murine $(\mathrm{m})$ OSM is exclusively mediated by the OSMR/gp130 complex, while mOSM cannot bind to the LIFR/gp130 complex (Lindberg et al. 1998, Tanaka et al. 1999, Wang et al. 2000). Therefore, experiments using hOSM in murine cell systems exhibit effects mediated by the LIFR/gp130 complex, while experiments using mOSM in murine cell systems exhibit effects mediated by the OSMR/gp130 complex. Thus, the signaling pathway induced by hOSM or mOSM in murine cell systems is exclusively different.

OSM has been reported to demonstrate inhibitory or stimulatory effects on cell growth in different cell types, as has recently been reviewed (Gomez-Lechon 1999, Tanaka \& Miyajima 2003). Inhibition of cell growth by OSM has been reported in solid tissue tumor cells, melanoma cells, glioma cells, cerebral meningioma cells, normal and tumoral mammary cells and endothelial cells. In contrast, stimulation of cell growth by OSM has been reported in fibroblasts, smooth muscle cells, AIDS-related Kaposi's sarcoma cells and plasmocytoma cells (Gomez-Lechon 1999, Tanaka \& Miyajima 2003). It has been suggested that OSM induces apoptosis in human primary neuronal cells (Ensoli et al. 1999), as well as inhibiting apoptosis in human osteoblastic cells and lung fibroblasts (Bellido et al. 1998, Scaffidi et al. 2002). The divergent effects of OSM on cell growth and apoptosis might, in part, be due to different patterns of OSMR/gp130 and LIFR/gp130 complex expression and activation in various cell types. This phenomenon has not been taken into account by most of these studies.

In the current study we investigated the effects of mOSM on murine adrenocortical Y-1 tumor cells, thus using a unique cell culture model to study the specific effects of the OSMR/gp130 receptor complex. We demonstrate that adrenocortical Y-1 tumor cells express the OSMR/gp130 complex and that mOSM induces Jak-STAT signaling in these cells. Incubation with mOSM induces apoptosis of adrenocortical Y-1 tumor cells as shown by caspase-3 cleavage and poly(ADP-ribose) polymerase (PARP) cleavage. The decrease in cell number following incubation with $\mathrm{MOSM}$ is reversed by preincubation with the Jak2 inhibitor, AG490, and the general caspase inhibitor, Z-VAD-FMK. These data demonstrate Jak activation and subsequent caspase activation to be essential for mOSM-induced apoptosis in adrenocortical Y-1 tumor cells. The putative role of OSM as an immunotherapeutic agent in human adrenocortical cancer remains to be elucidated.

\section{Materials and Methods}

\section{Materials}

Cell culture plastic ware was from Becton Dickinson (Heidelberg, Germany), while culture media and all other cell culture reagents were from PAA Laboratories (Linz, Austria). Recombinant mOSM, hOSM and murine leukemia inhibitory factor (mLIF) were purchased from R\&D Systems (Minneapolis, MN, USA). Antibodies against pSTAT3 and pSTAT1 were from Upstate Biotechnology (Lake Placid, NY, USA). Antibodies against pSTAT5, PARP and caspase-3 were from Cell Signaling, Cummings Center (Beverly, MA, USA). Antibodies against STAT3, STAT1 and STAT5 were from Santa Cruz Biotechnology (Santa Cruz, CA, USA). Horseradish peroxidase conjugated secondary antibodies to mouse or rabbit IgG and chemiluminescent substrate SuperSignal West Dura Extended Duration Substrate were from Pierce (Rockford, IL, USA). The Jak2 inhibitor, AG490, was from Calbiochem (Schwalbach, Germany) and the general caspase inhibitor, Z-VAD-FMK, was from Bachem (Heidelberg, Germany).

\section{Cell culture}

Murine adrenocortical Y-1 tumor cells were originally obtained from ATCC (Manassas, VA, USA). Y-1 cells were grown in complete medium (HAM'S F10 medium supplemented with $2.5 \%$ fetal calf serum and $15 \%$ horse serum) in a $5 \% \mathrm{CO}_{2}$ atmosphere. For the experiments, cells were seeded and grown for $24 \mathrm{~h}$ or $48 \mathrm{~h}$, followed by serum depletion (HAM'S F10 medium with $0 \cdot 2 \%$ BSA) overnight. Then, cytokines were added with fresh serumdepleted medium and samples collected at appropriate time points.

\section{Cell proliferation assay system}

Y-1 cells $\left(0 \cdot 3 \times 10^{6}\right)$ were plated in 6-well plates. After an initial incubation for $24 \mathrm{~h}$ in complete HAM'S F10 medium, cells were cultivated for a further $24 \mathrm{~h}$ in serum-depleted medium, before agents for treatment were added with fresh serum-depleted medium for another $24 \mathrm{~h}$. Afterwards, cells of each treatment group were trypsinated, harvested and resuspended in equal volumes, and $10^{5}$ cells per group were replated in 96-well plates and grown for $24 \mathrm{~h}$. To determine the relative number of viable cells in each group, CellTiter 96 aqueous cell proliferation kit (Promega) was used as described by the manufacturer. After $4 \mathrm{~h}$ of incubation with CellTiter 96 aqueous solution, absorbance at $492 \mathrm{~nm}$ was determined using an ELISA plate reader.

\section{$R T-P C R$}

RT was performed from mRNA samples using M-MLV Reverse Transcriptase (Invitrogen, Karlsruhe, Germany) according to the manufacturer's instructions. PCR was performed from cDNA probes on a GeneAmp PCR System 2400 using AmpliTaq DNA Polymerase (PerkinElmer, Foster City, CA, USA) and DMSO at a final 
concentration of $5 \%$. An initial denaturation step $\left(94^{\circ} \mathrm{C}\right.$, $3 \mathrm{~min}$ ) was followed by 40 PCR cycles (denaturation $94{ }^{\circ} \mathrm{C}, 1 \mathrm{~min}$; annealing at appropriate temperature, $1 \mathrm{~min}$; extension $72^{\circ} \mathrm{C}, 1 \mathrm{~min}$ ) and terminated by a single elongation step at $72{ }^{\circ} \mathrm{C}$ for $10 \mathrm{~min}$. A $563 \mathrm{nt}$ fragment of the murine OSMR cDNA (nt 94-657, Genebank Accession AF058805) was generated with a specific primer pair (sense 5'-AATGGCTTTCTCTGTGGTCCTTCA-3', antisense $5^{\prime}$-CGTTCTACTCGGTTAGGTACCTC-3') at an annealing temperature of $58^{\circ} \mathrm{C}$. A $315 \mathrm{nt}$ fragment of the murine LIFR cDNA (nt 2618-2935, Genebank Accession NM_013584), was generated with a specific primer pair (sense 5'-GAGCATCCTTTGCTATCGGA AGC-3', antisense $5^{\prime}$-CGTTATTTCCTCCTCGATG ATGG-3') at an annealing temperature of $56^{\circ} \mathrm{C}$. A $689 \mathrm{nt}$ fragment of the murine gp130 cDNA (nt 1863-2552, Genebank Accession X62646), was generated with a specific primer pair (sense 5'-CGTACACAGATGAAGG TGGGAAAG-3', antisense 5'-CTTCAGGCTGACTG CAGTTCTGC-3') at an annealing temperature of $58^{\circ} \mathrm{C}$.

\section{Luciferase assay}

Transient transfection of Y-1 cells with a $-2757 /+929$ murine SOCS-3 promoter-luciferase construct in pGL3 Basic vector was performed with Lipofectamine (Invitrogen, Carlsbad, CA, USA) as described recently (Auernhammer et al. 1999, 2003). Following transfection, cells were grown for another $24 \mathrm{~h}$ before mOSM, mLIF or hOSM at a concentration of $10 \mathrm{ng} / \mathrm{ml}$, each, were added in serum-depleted medium for 6 h. Following stimulation, supernatants were collected and luciferase activities were quantitated. Relative increase of untreated vs treated luciferase activity was calculated for each experiment.

\section{Protein extraction and Western blotting}

Protein extraction and Western blotting were performed as described recently (Auernhammer et al. 2003). Briefly, cells were lysed in $500 \mu \mathrm{l}$ lysis buffer $(50 \mathrm{mM}$ HEPES, $150 \mathrm{mM} \mathrm{NaCl}, 10 \mathrm{mM}$ EDTA, $10 \mathrm{mM} \mathrm{Na} \mathrm{N}_{2} \mathrm{O}_{7}$, $100 \mathrm{mM} \mathrm{NaF}, 2 \mathrm{mM}$ sodium orthovanadate, $\mathrm{pH} 7 \cdot 4$ ) containing 1\% Triton X-100, $1 \mathrm{mM}$ phenylmethylsulfonylfluoride, $2 \mu \mathrm{g} / \mathrm{ml}$ aprotinin and $20 \mu \mathrm{M}$ leupeptin. The lysates were centrifuged at $13000 \mathrm{~g}$ for $10 \mathrm{~min}$ at $4{ }^{\circ} \mathrm{C}$ and supernatants were diluted 1:1 with SDS sample buffer (0.25 M Tris $\mathrm{HCl}, 40 \%$ glycerol, 2\% sodium dodecyl sulfate (SDS), 1\% dithiothreitol, bromophenol blue, $\mathrm{pH}$ 8.8). Samples were boiled for $5 \mathrm{~min}$ and separated on a $10 \%$ SDS polyacrylamide gel. Proteins were electrotransferred in 60 min onto PVDF membranes (Immobilone; Millipore, Eschboon, Germany) using a semi-dry Western blot technique. Membranes were blocked for $30 \mathrm{~min}$ in TBS-T buffer (0.02 M Tris-HCl, $0 \cdot 15 \mathrm{M} \mathrm{NaCl,} 2 \%$ Tween 20, 0.01\% sodium azide). The blocked membranes were incubated overnight in appropriate dilutions (PBS-T;

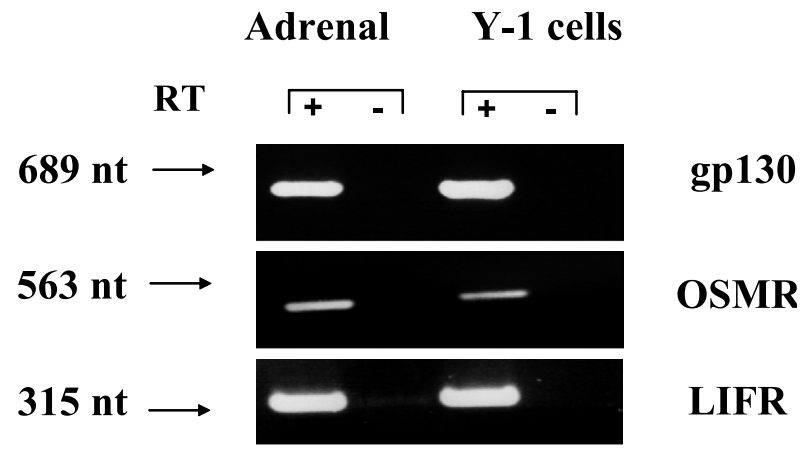

Figure 1 Expression of gp130, OSMR and LIFR mRNA in murine adrenocortical Y-1 cells and murine adrenal tissue. RT-PCR was repeatedly performed from three different RNA samples. RT+, with RT; RT - , without RT. A 689 nt fragment of the murine gp130 CDNA, a 563 nt fragment of the murine OSMR cDNA and a 315 nt fragment of the murine LIFR cDNA were generated. Specificity of RT-PCR-generated bands was verified by sequencing.

0.05 $\mathrm{M}$ sodium phosphate, $0 \cdot 15 \mathrm{M} \mathrm{NaCl}, 2 \%$ Tween 20 , $\mathrm{pH} 7)$ of antibodies against pSTAT1 (1:10 000), pSTAT3 (1:40 000), pSTAT5 (1:5000), PARP (1:1000) and caspase-3 (1:1000). After washing with PBS, the membranes were incubated with a peroxidase conjugated secondary antibody (goat anti-mouse or donkey antirabbit, depending on the primary antibody, 1:25 000 each) for $2 \mathrm{~h}$. The blots were washed and immersed in the chemiluminescent substrate for $30 \mathrm{~min}$ and exposed to XOMAT-AR film (Eastman Kodak, Rochester, NY, USA). Afterwards, the membranes were stripped and incubations with antibodies to STAT-1 (1:20 000), STAT3 $(1: 40000)$ and STAT5 $(1: 40000)$ were performed as described above.

\section{Statistical analysis}

Statistical analysis was performed with JMP $5 \cdot 0 \cdot 1$ software (SAS Institute Inc., Cary, NC, USA). The mean of a single treatment group was compared with the mean of a single control group with Student's $t$-test, and $P<0.05$ was considered statistically significant. The data are expressed as the mean \pm S.E. of independently performed experiments.

\section{Results}

Expression of OSMR, LIFR and gp $130 \mathrm{mRNA}$

Using RT-PCR, expression of gp130, OSMR and LIFR was found in mRNA derived from murine adrenocortical Y-1 tumor cells and adrenal tissue of C57B16 mice respectively (Fig. 1). A $689 \mathrm{nt}$ fragment of the murine gp130 cDNA (nt 1863-2552, Genebank Accession X62646), a $563 \mathrm{nt}$ fragment of the murine OSMR cDNA (nt 94-657, Genebank Accession AF058805) and a $315 \mathrm{nt}$ 


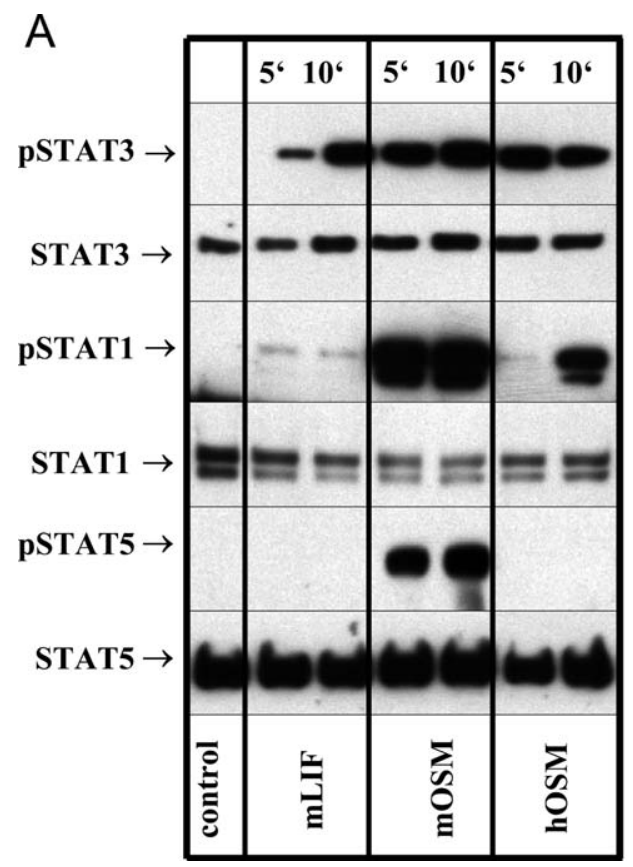

B

Figure $2 \mathrm{mLIF}, \mathrm{mOSM}$ and hOSM induce STAT protein activation and SOCS-3 promoter activity in adrenocortical Y-1 tumor cells. (A) Adrenocortical Y-1 cells were treated with $10 \mathrm{ng} / \mathrm{ml} \mathrm{mLIF,} \mathrm{mOSM} \mathrm{or} \mathrm{hOSM} \mathrm{for} 5$ and 10 min. Tyrosine phosphorylated STAT3, STAT1 and STAT5 were demonstrated by specific antibodies. Equal protein loading was verified by the use of antibodies against total STAT3, STAT1 and STAT5. A representative Western blot out of three independently performed experiments is demonstrated. (B) Y-1 cells were transiently transfected with a $-2757 /+929$ murine SOCS-3 promoter-luciferase construct and incubated with $10 \mathrm{ng} / \mathrm{ml} \mathrm{mLIF}, \mathrm{mOSM}$ or hOSM for $6 \mathrm{~h}$. Activity of stimulated cells was calculated as fold increase in comparison with the reporter gene activity of unstimulated controls which was taken as $1 \cdot 0$. Demonstrated are the mean values of three independently performed experiments with $n=3$ per treatment group. Significance of cytokine-stimulated SOCS-3 promoter activity vs untreated control is indicated with asterisks: ${ }^{* *} P<0 \cdot 01,{ }^{* *} P<0 \cdot 001$.

fragment of the murine LIFR cDNA (nt 2618-2935, Genebank Accession NM_013584) were generated. Appropriate sized bands derived from adrenocortical Y-1 tumor cell mRNA were cloned in $\mathrm{pCR} 2 \cdot 1$ vector and full-length sequenced to verify their specificity.

\section{STAT protein phosphorylation}

Murine OSM significantly stimulated tyrosine phosphorylation of STAT5, STAT3 and STAT1 at 5 and $10 \mathrm{~min}$ (Fig. 2A). In contrast, mLIF and hOSM also significantly stimulated tyrosine phosphorylation of STAT3 at 5 and $10 \mathrm{~min}$, but showed only a minor effect on tyrosine phosphorylation of STAT1. No effect of mLIF and hOSM was observed on tyrosine phosphorylation of STAT5 (Fig. 2A).

\section{SOCS-3 expression}

Luciferase activity of a $-2757 /+929$ murine SOCS-3 promoter-luciferase construct was induced by mOSM $4 \cdot 5 \pm 0 \cdot 3$-fold $(P<0 \cdot 001)$, while mLIF and hOSM caused only a $2 \cdot 2 \pm 0 \cdot 2$-fold $(P<0 \cdot 001)$ and $2 \cdot 0 \pm 0 \cdot 1$-fold $(P<0 \cdot 001)$ increase respectively (Fig. 2B).

\section{Cell viability and cell numbers}

Untreated Y-1 cells were all adherent to the plastic ware, while after $24 \mathrm{~h}$ of incubation with mOSM $(10 \mathrm{ng} / \mathrm{ml})$ a large proportion of $\mathrm{Y}-1$ cells was detached (Fig. 3A); in contrast, no effect on cell adherence was observed by incubation with MLIF and hOSM (data not shown).

Using a cell proliferation assay system, cell numbers were defined as $100 \%$ in untreated controls of each experiment series. The following experimental series were performed. (i) Incubation of Y-1 cells for $24 \mathrm{~h}$ with $10 \mathrm{ng} / \mathrm{ml}$ mOSM significantly decreased cell numbers to $37 \pm 3 \%$ vs control, while mLIF and hOSM had no significant effect $(80 \pm 19 \%$ and $81 \pm 15 \%)$ (Fig. 3B). (ii) The effect of MOSM was dose-dependent as $0 \cdot 01,0 \cdot 1,1 \cdot 0$ and $10 \cdot 0 \mathrm{ng} / \mathrm{ml} \mathrm{mOSM}$ caused a decline in $\mathrm{Y}-1$ cell numbers to $99 \pm 2 \%, 84 \pm 9 \%, 50 \pm 7 \%$ and $43 \pm 5 \%$ respectively vs control (Fig. 3C). (iii) Preincubation of Y-1 cells with the Jak2 inhibitor AG490 $(100 \mu \mathrm{M})$ prior to 
A

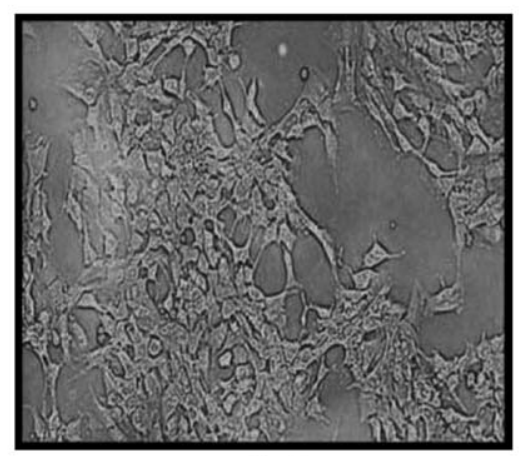

control

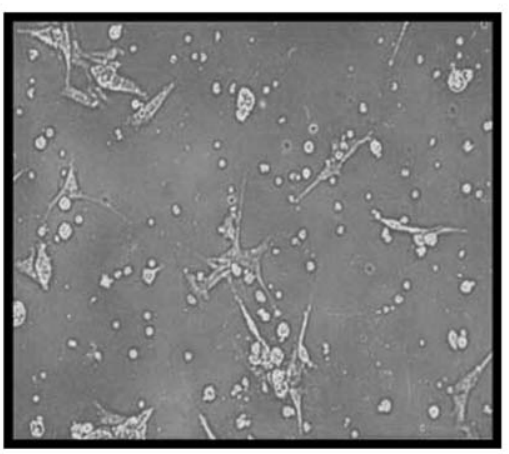

mOSM

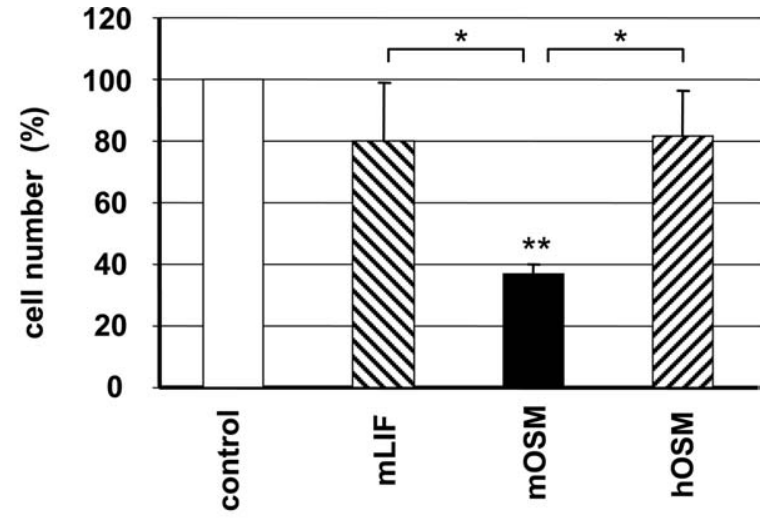

C

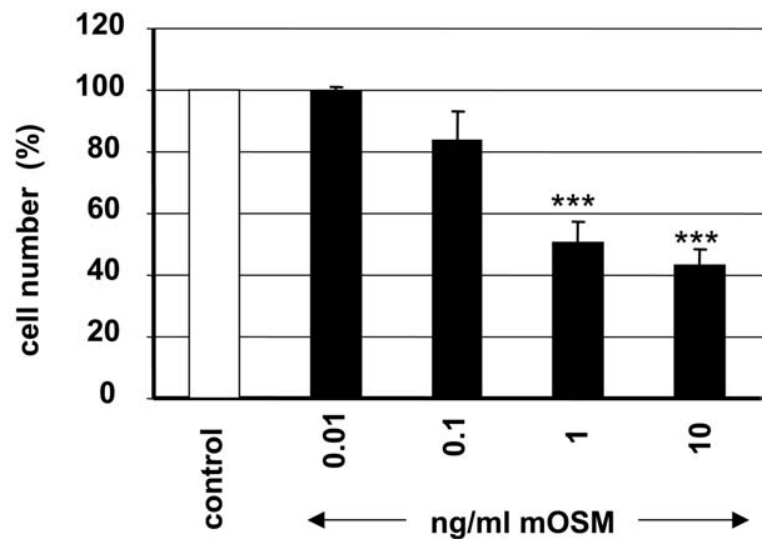

Figure 3 mOSM induces cell death in adrenocortical Y-1 tumor cells. Y-1 cells $\left(10^{3}\right)$ were plated in individual wells in a 96-well plate. The cells were incubated for $24 \mathrm{~h}$ in HAM'S F10 medium containing $15 \%$ horse serum and $2.5 \%$ FCS and then for a further $24 \mathrm{~h}$ in serum-free medium. Cytokine treatment was performed with fresh serum-depleted medium for $24 \mathrm{~h}$. Cell viability was assessed using CellTiter 96 aqueous proliferation assay and absorbance at $490 \mathrm{~nm}$ was determined. Cell viability of the control group was set at $100 \%$ and the relative viability of the cytokine-treated groups was calculated in comparison with the control group. (A) Y-1 cells treated for $24 \mathrm{~h}$ with $10 \mathrm{ng} / \mathrm{ml} \mathrm{mOSM}$ compared with controls. (B) Y-1 cells were treated with $10 \mathrm{ng} / \mathrm{ml} \mathrm{mLIF}$, mOSM or hOSM for $24 \mathrm{~h}$. Cell viability (mean values \pm S.E.) of four independently performed experiments is shown. Significant differences are indicated with asterisks: ${ }^{\star} P<0 \cdot 05$, ${ }^{* *} P<0 \cdot 01$. (C) Dose-dependent effects of $0 \cdot 01$ to $10 \mathrm{ng} / \mathrm{ml} \mathrm{mOSM}$. Y-1 cells were treated with the indicated mOSM concentrations for $24 \mathrm{~h}$. Cell viability (mean values \pm S.E.) of three independently performed experiments is shown and significant differences are indicated with asterisks: ${ }^{* *} P<0 \cdot 001$.

incubation with mOSM $(10 \mathrm{ng} / \mathrm{ml})$ almost completely abolished the suppressive effect of mOSM on Y-1 cell numbers (Fig. 4A). While incubation of Y-1 cells for $24 \mathrm{~h}$ with MOSM significantly decreased cell numbers to $53 \pm 7 \%$ vs control, cell numbers of Y-1 cells preincubated with $100 \mu \mathrm{M}$ AG490 prior to incubation with $10 \mathrm{ng} / \mathrm{ml}$ mOSM were $87 \pm 4 \%$ of control $(P<0.001$ vs mOSM; not significant vs untreated control). (iv) Preincubation of Y-1 cells with the general caspase inhibitor Z-VAD-FMK $(42 \mu \mathrm{M})$ prior to incubation with mOSM $(10 \mathrm{ng} / \mathrm{ml})$ almost completely abolished the suppressive effect of mOSM on Y-1 cell numbers (Fig. 4B). While incubation of Y-1 cells for $24 \mathrm{~h}$ with mOSM significantly decreased cell numbers to $65 \pm 3 \%$ vs control, cell numbers of $\mathrm{Y}-1$ cells preincubated with $42 \mu \mathrm{M}$ Z-VAD-FMK prior to incubation with $10 \mathrm{ng} / \mathrm{ml} \mathrm{mOSM}$ were $92 \pm 6 \%$ of con- trol $(P<0.001$ vs mOSM; not significant vs untreated control).

\section{Cleavage of caspase- 3 and PARP}

In untreated Y-1 cells no cleaved caspase-3 and PARP products were detected. Following incubation of Y-1 cells with $10 \mathrm{ng} / \mathrm{ml} \mathrm{mOSM}$ for 2,6 and $24 \mathrm{~h}$, respective cleavage products of caspase-3 (Fig. 5A) and PARP (Fig. 5B) were detectable at $24 \mathrm{~h}$.

\section{Discussion}

We have been able to show for the first time that the OSMR/gp130 ligand mOSM induces apoptosis in murine adrenocortical Y-1 tumor cells. 
A

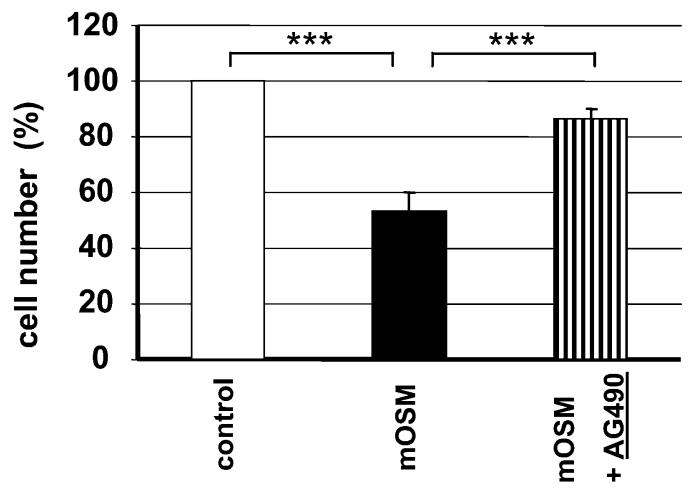

B

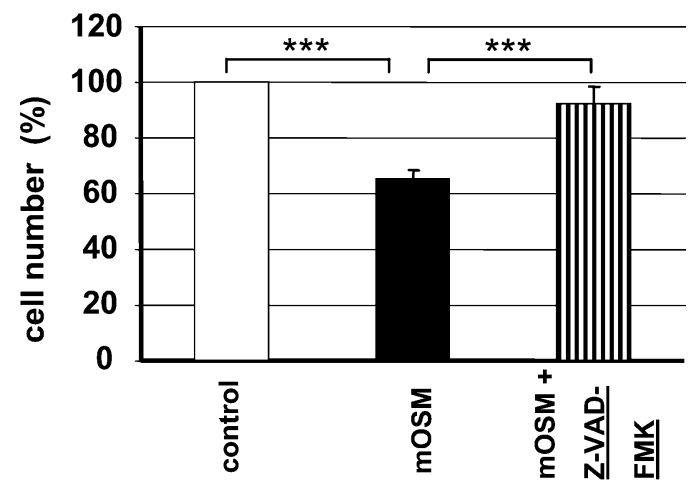

Figure 4 The Jak2 inhibitor, AG490, and the general caspase inhibitor, Z-VAD-FMK, rescue adrenocortical Y-1 tumor cells from mOSM-induced cell death. Y-1 cells $\left(10^{3}\right)$ were plated in individual wells in a 96 -well plate. The cells were incubated for $24 \mathrm{~h}$ in HAM'S F10 medium containing 15\% horse serum and 2.5\% FCS and then for a further $24 \mathrm{~h}$ in serum-free medium. Prior to treatment with $\operatorname{mOSM}(10 \mathrm{ng} / \mathrm{ml})$ which was performed with fresh serum-depleted medium for $24 \mathrm{~h}$, cells were incubated with specific inhibitors for $30 \mathrm{~min}$. Cell viability was assessed using CellTiter 96 aqueous proliferation assay and absorbance at $490 \mathrm{~nm}$ was determined. Cell viability of the control group was set at $100 \%$ and the relative viability of the mOSM-treated groups was calculated in comparison with the control group. (A) Y-1 cells were treated with the Jak2 inhibitor AG490 $(100 \mu \mathrm{M})$ for $30 \mathrm{~min}$ prior to stimulation with $10 \mathrm{ng} / \mathrm{ml} \mathrm{mOSM}$ for $24 \mathrm{~h}$. Cell viability (mean values \pm S.E.) of six independently performed experiments is shown. Significant differences are indicated with asterisks: ${ }^{* *} P<0 \cdot 001$. (B) Y-1 cells were treated with the general caspase inhibitor Z-VAD-FMK $(42 \mu \mathrm{M})$ for 30 min prior to stimulation with $10 \mathrm{ng} / \mathrm{ml}$ mOSM for $24 \mathrm{~h}$. Cell viability (mean values \pm S.E.) of seven independently performed experiments is shown. Significant differences are indicated with asterisks: ${ }^{* *} P<0 \cdot 001$.

Murine OSM is a specific ligand to the OSMR/gp130 complex. hOSM and mLIF are specific LIFR/gp130 ligands in the murine system, while human OSM is able to exert its effects through OSMR as well as LIFR complexes in the human system (Lindberg et al. 1998, Tanaka et al. 1999, Wang et al. 2000). The OSMR, LIFR and gp130 receptor subunits are expressed on adrenocortical Y-1 tumor cells (Fig. 1). Incubation of $\mathrm{Y}-1$ cells with the OSMR/gp130 ligand mOSM resulted in potent activation of STAT5, STAT3 and STAT1 (Fig. 2A). In contrast, incubation with the LIFR/gp130 ligands hOSM and mLIF resulted only in STAT3 and to a lesser extent also in STAT1 phosphorylation (Fig. 2A). The 5 '-region of murine SOCS-3 harbors a functionally essential STATbinding element located at -72 to $-64 \mathrm{nt}$, which can bind STAT1/3 (Auernhammer et al. 1999) as well as STAT5 (Emanuelli et al. 2000). Induction of the STATdependent SOCS-3 promoter activity was induced by mOSM more extensively than by hOSM or mLIF (Fig. 2B).

Incubation of adrenocortical Y-1 cells with mOSM resulted in the detachment of a significant number of cells (Fig. 3A) and dose-dependently decreased the number of viable cells (Fig. 3C). This effect was specific for mOSM, as it was not observed with hOSM or MLIF (Fig. 3B). The mOSM-induced decline in viable cells was abolished by pretreatment with the Jak2 inhibitor, AG490 (Fig. 4A), indicating the observed effects of MOSM on Y-1 cells to be Jak dependent. Growth inhibition of OSM has been reported to be STAT3 dependent in several cell lines
(Hutt \& DeWille 2002, Lundquist et al. 2003, Zhang et al. 2003), but discrepant results have also been reported (Halfter et al. 2000). We cannot exclude the possibility that in addition to specific induction of apoptosis cell cycle arrest and growth inhibition might also contribute to the effects of mOSM on Y-1 cells. Cleavage of caspase-3 and of PARP (Fig. 5A and B), as well as the rescue of the mOSM-induced decline in viable cell numbers by the general caspase inhibitor, Z-VAD-FMK (Fig. 4B) strongly indicate induction of apoptosis by MOSM in adrenocortical Y-1 tumor cells.

In summary, OSM has been reported to have cellspecific antiproliferative as well as proliferative effects in a variety of different cell systems (Gomez-Lechon 1999, Tanaka \& Miyajima 2003). However, since hOSM binds to both the OSMR/gp130 and to the LIFR/gp130 complex (Lindberg et al. 1998, Tanaka et al. 1999, Wang et al. 2000), the specific effects of OSM mediated by the OSMR/gp130 complex remain unclear. Utilizing the specific and exclusive binding of mOSM to the murine OSMR/gp130 complex, we therefore present in our study in murine adrenocortical tumor cells a specific proapoptotic effect of OSM which is mediated specifically through the OSMR/gp130 complex. Future studies using OSMR knockout animals (Tanaka et al. 2003) or an in vivo $\mathrm{Y}-1$ tumor model in nude mice will further enlighten the putative role of the OSMR/gp130 ligand MOSM in apoptosis. A cell-specific apoptotic effect of OSM on adrenocortical cells might be a potentially important/ valuable mechanism for the development of a specific 
A

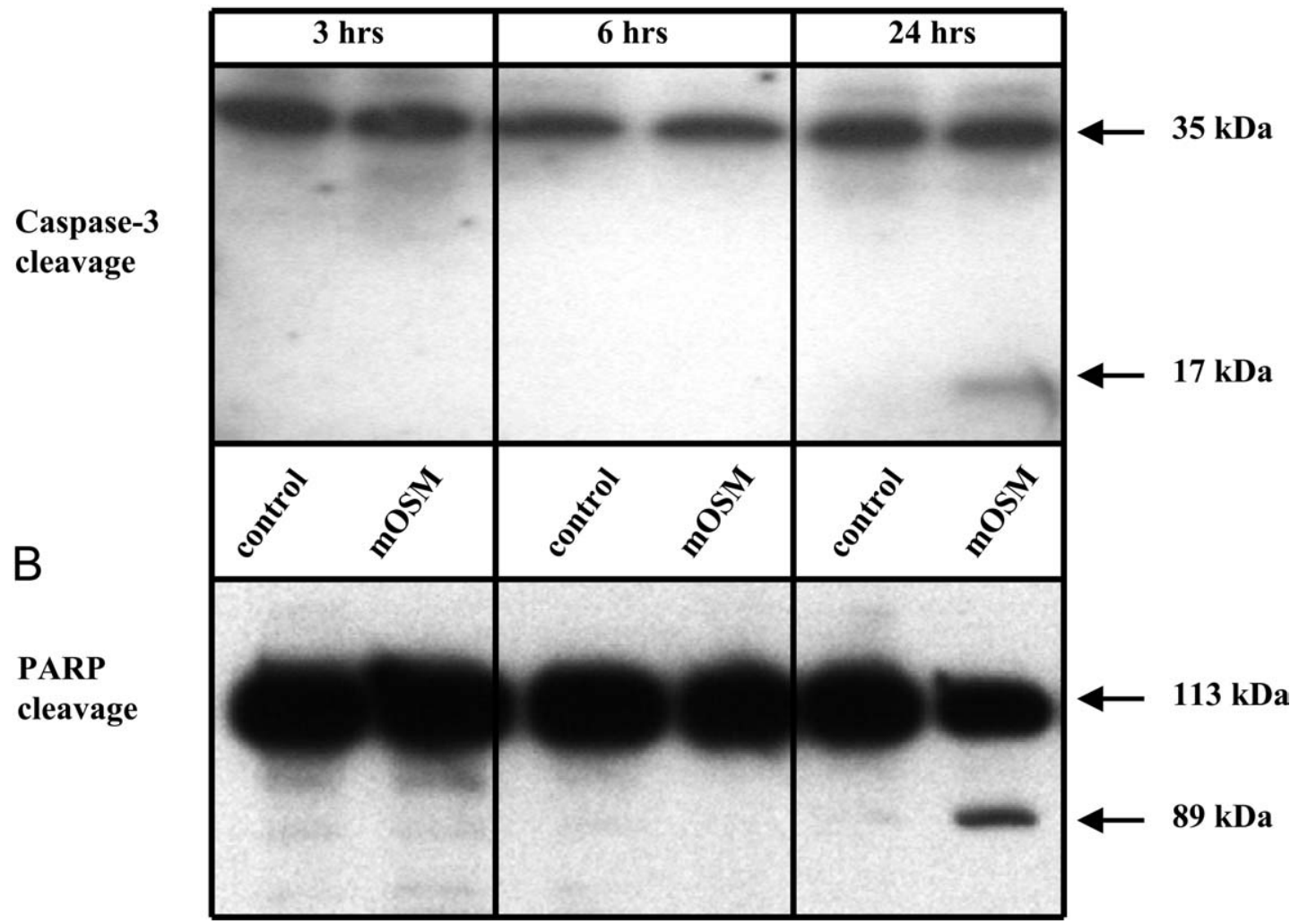

Figure 5 mOSM induces caspase- 3 and PARP cleavage in adrenocortical $\mathrm{Y}-1$ tumor cells. Adrenocortical $\mathrm{Y}$ - 1 cells were treated with $10 \mathrm{ng} / \mathrm{ml}$ mOSM for $3 \mathrm{~h}, 6 \mathrm{~h}$ and $24 \mathrm{~h}$. Total and cleaved caspase- 3 (A) and PARP (B) were detected by the use of specific antibodies. A representative Western blot out of three independently performed experiments is demonstrated.

therapy for the highly malignant adrenocortical cancer. For hOSM, future studies will have to specify whether the observed effects in distinct cells are due to activation of the OSMR/gp130 or the LIFR/gp130 complex. A specific OSMR/gp130 ligand devoid of LIFR/gp130 affinity engineered by site-directed mutagenesis would also be valuable to further the study of growth inhibition and apoptosis in human cell systems. The putative role of OSMR ligands as an immunotherapeutic agent in human adrenocortical cancer remains to be elucidated.

\section{Acknowledgements}

This work contains parts of the unpublished doctoral thesis of $\mathrm{F}$ Dorn at the Ludwig-Maximilians-University of Munich, Germany.

\section{Funding}

This study was supported by grants from the Deutsche Forschungsgemeinschaft (AU 139/2-1) and FriedrichBaur Stiftung (0068/2000 and 0055/2001).

\section{References}

Auernhammer CJ \& Melmed S 2000 Leukemia-inhibitory factor neuroimmune modulator of endocrine function. Endocrine Reviews $21313-345$.

Auernhammer CJ, Bousquet C \& Melmed S 1999 Autoregulation of pituitary corticotroph SOCS-3 expression: characterization of the murine SOCS-3 promoter. PNAS 96 6964-6969.

Auernhammer CJ, Isele NB, Kopp FB, Spoettl G, Cengic N, Weber MM, Senaldi G \& Engelhardt D 2003 Novel neurotrophin-1/B cell-stimulating factor-3 (cardiotrophin-like cytokine) stimulates corticotroph function via a signal transducer and activator of transcription-dependent mechanism negatively regulated by suppressor of cytokine signaling-3. Endocrinology 144 1202-1210.

Bellido T, O’Brien CA, Roberson PK \& Manolagas SC 1998 Transcriptional activation of the p21 (WAF1,CIP1, SDI1) gene by interleukin-6 type cytokines. A prerequisite for their pro-differentiating and anti-apoptotic effects on human osteoblastic cells. Journal of Biological Chemistry 273 21137-21144.

Emanuelli B, Peraldi P, Filloux C, Sawka-Verhelle D, Hilton D \& Van Obberghen E 2000 SOCS-3 is an insulin-induced negative regulator of insulin signaling. Journal of Biological Chemistry 275 15985-15991.

Ensoli F, Fiorelli V, DeCristofaro M, Santini Muratori D, Novi A, Vannelli B, Thiele CJ, Luzi G \& Aiuti F 1999 Inflammatory cytokines and HIV-1-associated neurodegeneration: oncostatin-M 
produced by mononuclear cells from HIV-1-infected individuals induces apoptosis of primary neurons. Journal of Immunology 162 6268-6277.

Gomez-Lechon MJ 1999 Oncostatin M: signal transduction and biological activity. Life Sciences $\mathbf{6 5} 2019-2030$.

Halfter H, Stogbauer F, Friedrich M, Serve S, Serve H \& Ringelstein EB 2000 Oncostatin M-mediated growth inhibition of human glioblastoma cells does not depend on STAT3 or on mitogen-activated protein kinase activation. Journal of Neurochemistry 75 973-981.

Heinrich PC, Behrmann I, Haan S, Hermanns HM, Muller-Newen G \& Schaper F 2003 Principles of IL-6-type cytokine signalling and its regulation. Biochemical Journal 374 1-20.

Hutt JA \& DeWille JW 2002 Oncostatin M induces growth arrest of mammary epithelium via a CCAAT/enhancer-binding protein delta-dependent pathway. Molecular Cancer Therapentics 1 601-610.

Lindberg RA, Juan TS, Welcher AA, Sun Y, Cupples R, Guthrie B \& Fletcher FA 1998 Cloning and characterization of a specific receptor for mouse oncostatin M. Molecular and Cellular Biology 18 $3357-3367$.

Lundquist A, Barre B, Bienvenu F, Hermann J, Avril S \& Coqueret O 2003 Kaposi sarcoma-associated viral cyclin K overrides cell growth inhibition mediated by oncostatin $\mathrm{M}$ through STAT3 inhibition. Blood 101 4070-4077.

Scaffidi AK, Mutsaers SE, Moodley YP, McAnulty RJ, Laurent GJ, Thompson PJ \& Knight DA 2002 Oncostatin M stimulates proliferation, induces collagen production and inhibits apoptosis of human lung fibroblasts. British Journal of Pharmacology 136 793-801.

Tanaka M \& Miyajima A 2003 Oncostatin M, a multifunctional cytokine. Reviews of Physiology Biochemistry and Pharmacology 149 39-52.

Tanaka M, Hara T, Copeland NG, Gilbert DJ, Jenkins NA \& Miyajima A 1999 Reconstitution of the functional mouse oncostatin $\mathrm{M}$ (OSM) receptor: molecular cloning of the mouse OSM receptor beta subunit. Blood 93 804-815.

Tanaka M, Hirabayashi Y, Sekiguchi T, Inoue T, Katsuki M \& Miyajima A 2003 Targeted disruption of oncostatin M receptor results in altered hematopoiesis. Blood 102 3154-3162.

Wang Y, Robledo O, Kinzie E, Blanchard F, Richards C, Miyajima A \& Baumann H 2000 Receptor subunit-specific action of oncostatin $\mathrm{M}$ in hepatic cells and its modulation by leukemia inhibitory factor. Journal of Biological Chemistry 275 25273-25285.

Zhang F, Li C, Halfter H \& Liu J 2003 Delineating an oncostatin M-activated STAT3 signaling pathway that coordinates the expression of genes involved in cell cycle regulation and extracellular matrix deposition of MCF-7 cells. Oncogene 22 894-905.

Received 28 August 2003

Accepted 11 December 2003

Made available online as an

Accepted Preprint 19 December 2003 